\title{
SYNTHESIS OF MATERIALS BY THE CONCENTRATED SOLAR RADIATION
}

\author{
M.S. Paizullakhanov ${ }^{1}$, Zh.Z. Shermatov ${ }^{1}$, E.Z. Nodirmatov ${ }^{1}$, O.T. Rajamatov ${ }^{1}$, F.N. Ernazarov ${ }^{1}$, \\ M.T. Sulaimanov ${ }^{1}$, Sh. Nurmatov ${ }^{1}$, N.N.Cherenda ${ }^{2,3}$ \\ ${ }^{1}$ Institute of Materials Science SPA "Physics-Sun" Academy of Sciences of the Republic of \\ Uzbekistan, 100084 Tashkent, Chingiza Aitmatova Str., 2-B, Uzbekistan, e-mail: fayz@ bk.ru \\ ${ }^{2}$ Belarusian State University, Nezavisimosti ave., 4, Minsk 220030, Belarus \\ ${ }^{3}$ South Ural State University, Lenin Ave., 76, Chelyabinsk 454080, Russia
}

\begin{abstract}
The influence of technological parameters of the Grand Solar Furnace on the structure and properties of materials synthesized from the melt have been studied in this work. It was found that the crystalline state, phase composition, microstructure and mechanical properties of pyroxene group material were strongly dependent on the flux density of solar radiation and cooling speed. The findings showed that homogeneous disperse microstructure with optimal combination of crystalline and amorphous phases received from the melt led to the wear resistance increase.
\end{abstract}

Key words: solar furnace, concentrated flow, synthesis, flux density, microstructure, pyroxene.

\section{INTRODUCTION}

The Sun is the main source of energy on Earth which power is incomparable with any other source. The Sun radiation power at the zenith is about $1360 \mathrm{~W} / \mathrm{m}^{2}$ close to the surface of the Earth. According to a simple calculation solar radiation collected from an area of $7.5 \mathrm{~m}^{2}$ is sufficient to generate power of $10 \mathrm{~kW}$. Every square meter oriented perpendicular to the sun rays accumulates more than $1 \mathrm{~kW}$ of the solar energy in ccentral Russia at noon in summer.

Analysis shows that burning of $200 \mathrm{~kg}$ of coal generates up to $1 \mathrm{~kW} / \mathrm{h}$ of the heat energy. The cost of $1 \mathrm{MW} / \mathrm{h}$ of heat energy is about US \$20. At the same time burning of this quantity of coal requires 0.53 tons of oxygen and discharges 0.7 tons of $\mathrm{CO}_{2}$ resulting in air pollution. Therefore, the use of solar power can give the technology with the energy saving- and environment preserving features.

The main restriction of the solar energy usage is the solar radiation inconstancy: equipment does not effective at night time and in cloudy weather. Uzbekistan is considered a "sunny" republic where number of sunny days reaches 260 in a year. There is one more factor that is particularly relevant for northern latitudes - seasonal differences in the length of the day. The duration of the day and night barely depends on the season for tropical and equatorial areas. At the same time in the middle latitude of Russia, and especially in the circumpolar regions, the shortest day is almost 2.5 times less than the longest one. Mirror-concentrating systems (MCS) are applied to increase efficiency of the solar energy usage. MCS are designed to capture and concentrate the radiation flux to a level ensuring its efficient conversion of sunlight into energy of the required type. The MCS application areas include thermal, technological and energy aspects. The MCS features are determined by the geometry of the concentrator as well as by the quality of the mirrors surface.

The main characteristics of MCS are the following:

1) Focal radiation density $E_{f}$ :

$$
E_{\mathrm{f}}=\rho_{\mathrm{ref}} \frac{1}{\varphi_{0}^{2}} \sin ^{2} \mathrm{U}_{\mathrm{m}} \mathrm{E}_{0} \text {, }
$$

where $\rho_{\text {ref }}$ is the concentrator reflectivity; $\mathrm{U}_{\mathrm{m}}$ is the maximum angle of paraboloid opening to the side, determined by the upper edge of the paraboloid (degrees); $\varphi_{0}$ is aperture angle of elementary sun beam (16 angular minutes); $\mathrm{E}_{0}$ is the solar radiation density $\left(\mathrm{W} / \mathrm{m}^{2}\right)$ 
2) The sunlight concentration degree in paraboloid

$$
\mathrm{n}=\left(\frac{\mathrm{D}}{\mathrm{d}}\right)^{2} \rho_{\text {ref }}
$$

where $\mathrm{D}$ is a diameter of the paraboloid reflector; $\mathrm{d}$ is diameter of the focal spot (taken as the size of the minor semi-axe of the focal spot). Optimal values of concentration degree typical for solar power plants are in the range of $1-10^{2}$ (Andreyev et.al., 1989). Focusing of the solar radiation increases its density, and changes its space distribution resulting in distribution changes at radiation-receiving surfaces.

Solar furnaces are widely used to achieve high temperatures (Fernández-González et.al, $2018 \mathrm{~b}$ ) for material processing (welding and cladding, surface treatment, treatment of coatings and surface hardening, powder metallurgy), synthesis and processing of non-metallic materials (ceramics, fullerenes, carbon nanotubes, calcium aluminate cements (Fernández-González et.al, 2018a) and lime production). As mentioned in these works, concentrated solar energy can be an alternative energy source in metallurgical processes (silicon and aluminum production).

When heated, the stream of concentrated light radiation sets special technological synthesis conditions, which can be used to obtain materials with desired properties. The coverage of concentrated light radiation when using mirror concentrators ranges from near IR $(\lambda=2-3 \mu \mathrm{m}$, quantum energy up to $0.4-0.6 \mathrm{eV})$ to near $\mathrm{UV}(\lambda=0.3-0.4 \mu \mathrm{m}$, quantum energy up to $3-4 \mathrm{eV})$. Therefore, if the bandgap of the oxide material goes over $4 \mathrm{eV}$, the entire solar energy will penetrate into the bulk of the material, and the energy absorption occurs due to the defects with layers within the bandgap. With a decrease in the band gap of the material, far more of the energy of the Sun is absorbed in a thin surface layer of the material, and owing to metallic conductivity, solar energy is absorbed only in a thin surface layer, thus generating giant temperature gradients in the material. Light reflection at the air-oxide interface also takes place. After melting, once a clear boundary of the liquid phase has formed, reflection can play a significant role in synthesizing materials. The liquid phase helps to transfer substances between grains and complete entire course of the reaction. Thus further investigation needs to be carried out in order to use solar energy processes as an alternative to the well-explored traditional processes.

The distinctive differences of solar technology from traditional ones are high heating rate, the purity of the products obtained, etc. These features determine the possibility of making improved ceramics, intermetallic composites, functional-gradient materials (Abdurakhmanov et.al, 2009; Abdurakhmanov et.al., 2012; Akbarov et.al., 2018; Atabaev et.al., 2015; Atabaev et.al., 2016; Paizullakhanov et.al., 2016; Paizullakhanov et.al., 2019; Riskiev et.al., 2015).

The effect of concentrated solar radiation on the synthesis from a melt of glass-crystalline materials from pyroxene group with improved mechanical properties was investigated in this work.

\section{MATERIALS AND METHODS}

Functional and technological capacities of the Grand Solar Furnace (GSF) (Fig. 1) with 1 MW of thermal power were used for processing and synthesis of materials. 

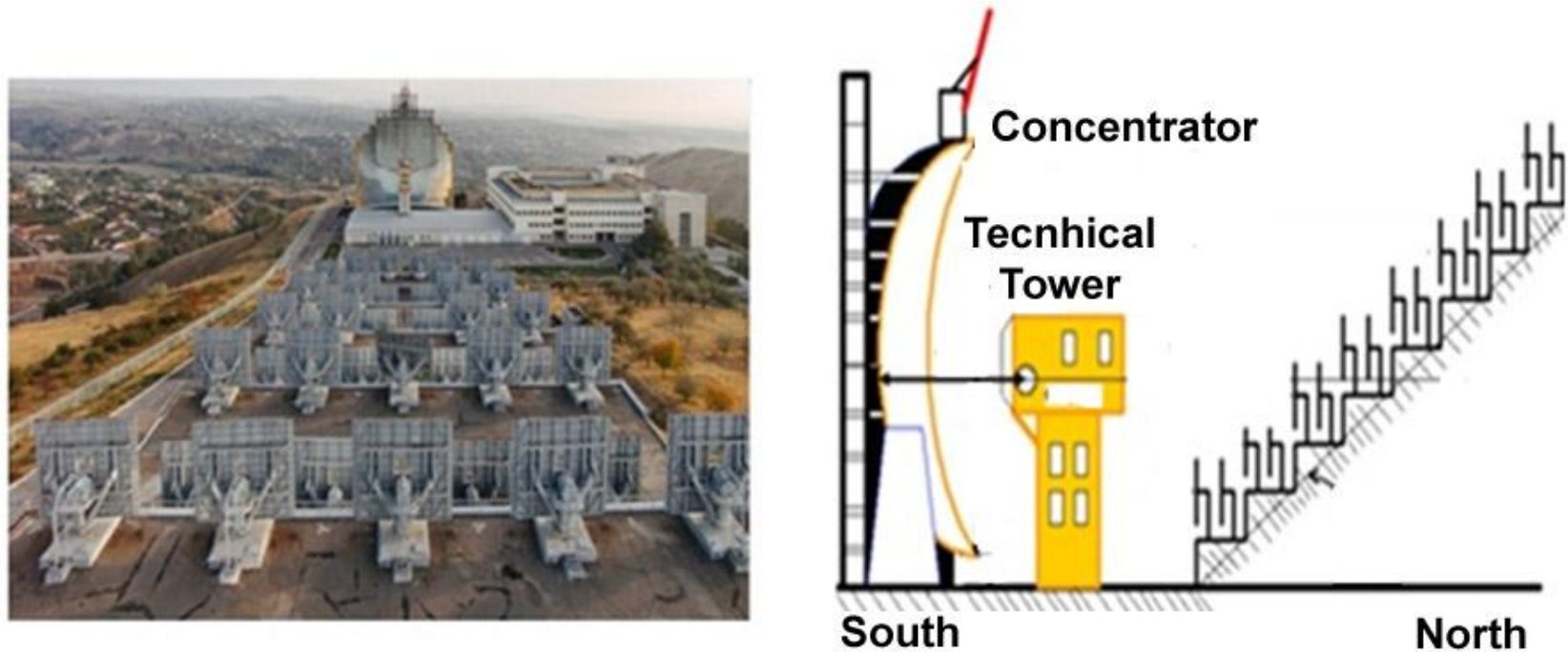

Fig. 1. Grand Solar Furnace with 1MW of thermal power.

The technology for processing and synthesis of materials in the GSF implied irradiation of the material fixed on the focal spot with a concentrated flow of high-density solar radiation. Irradiation facilitated heating of the material as a result of absorption of energy of the light quantum. Heating of the material caused its destruction - melting. The melt could be subject to further irradiation in order to increase its homogeneity. The melt could be cooled at different cooling rates, for example, by spontaneous cooling on the surface of a water-cooled substrate. The cooling rate reached $10^{2}$ deg / s. here, however it achieved $10^{3} \mathrm{deg} / \mathrm{s}$ when the melt had been poured into water. To achieve high cooling rates of the melt, the methods of special unbundling it with copper plates were used, which helped to raise the cooling rate up to almost $10^{4} \mathrm{deg} / \mathrm{s}$.

The density of solar radiation in the spot as well as the mean concentration of radiation in certain areas of the focal spot are deemed crucial parameters in terms of the process issues. The flux density in the spot of the Grand Solar Furnace and its variation during the day were defined (Fig. 2).

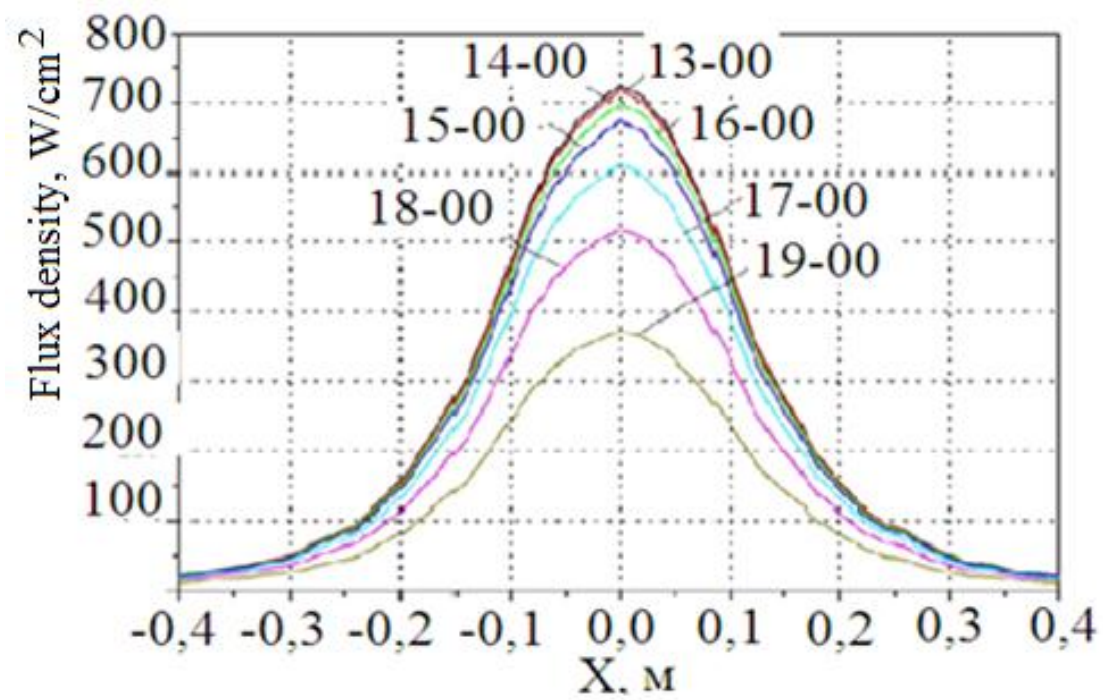

Fig.2. Variations of the energy density in the focal zone along the focus diameter $(\mathrm{X})$ of the Grand Solar Furnace, during the day (the numbers indicate time the measurements were made). 
To achieve a given density on the focal zone of the Grand Solar Furnace of a plane, illuminated by a concentrated solar radiation of a given density and distribution, it is important to be guided by the optical (absorption factor, emissivity) as well as by thermo-physical (melting temperature, thermal conductivity) characteristics of a material.

Table 1 shows the chemical composition of the initial basalt raw materials for melting in the Big Solar Furnace. Chemical composition was determined by standard analytical chemistry techniques.

Table 1

Chemical composition of basalt rocks

\begin{tabular}{|c|c|c|c|c|c|c|c|c|c|c|c|c|}
\hline \multicolumn{13}{|c|}{ Composition, mass. $\%$} \\
\hline 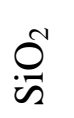 & $\stackrel{N}{O^{N}}$ & 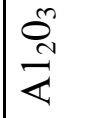 & $\sum_{i}^{00}$ & 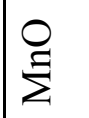 & త్ర & $\begin{array}{l}\text { O } \\
\stackrel{\text { Z }}{ }\end{array}$ & $\begin{array}{l}\text { 오 } \\
\text { ít }\end{array}$ & $\begin{array}{l}n \\
\delta^{n} \\
\alpha^{2}\end{array}$ & $\tilde{\mathscr{S}}$ & 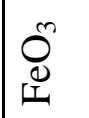 & $\begin{array}{l}\underset{N}{I} \\
\underset{1}{0}\end{array}$ & O \\
\hline 36,1 & 0,07 & 5,11 & 3,3 & 0,85 & 40,2 & 1,32 & 0,9 & 0,04 & 0,8 & 2,11 & 0,5 & 8,7 \\
\hline
\end{tabular}

The materials were melted in the Grand Solar Furnace on a water-cooled substrate within the range of concentrated solar radiation flows of $100-350 \mathrm{~W} / \mathrm{cm}^{2}$. The melt was quenched by cooling in water (Vcool $\sim 10^{3} \mathrm{deg} / \mathrm{sec}$.), through hardening on a water-cooled surface, upon which melting was done (Vcool $\sim 10^{2} \mathrm{deg} / \mathrm{sec}$.). The most complete melting could be observed, when the raw material was kept under a flux density of at least $150 \mathrm{~W} / \mathrm{cm}^{2}$ for $20 \mathrm{~min}$. The glass was more homogeneous at a flux density of $300 \mathrm{~W} / \mathrm{cm}^{2}$.

Differential thermal (DTA) and thermo-gravimetric methods for the analysis of oxides and rock waste were implemented on a Q-1500 D derivatograph.

An X-ray phase analysis of the feedstock and final products was carried out on a DRON-UM1 diffractometer with CuKa-radiation (20-10-60 deg.). Ya. A. Hiller's reference table was used for deciphering the X-ray diffraction patterns (Hiller, 1966).

Microstructural features of the objects of study were defined using ZEISS EVO electron microscope.

The values of abrasion, water absorption and tensile strength were determined using State Standard 31436-2011 "Hard rocks for crushed stone production for construction works. Technical requirements and test methods".

\section{FINDINGS AND DISCUSSION}

The analysis showed that fused at $200 \mathrm{~W} / \mathrm{cm}^{2}$ material (glass), after being quenched in water, appeared to be structureless - amorphous (Figure 3). However, the X-ray picture of the slowly cooled material demonstrates a barely expressed diffraction pattern derived from a blend of an amorphous phase and crystalline phases of monoclinic diopside $\mathrm{CaMgSi}_{2} \mathrm{O}_{6}(3.35,2.99,2.89,2.53$ A) and $\mathrm{CaMgFeO}_{3}(\mathrm{~d}=4.44,3.23,2.99,2.55 \AA$ ) $)$ augite, with domination of the latter (Fig. 4). In this case, the diffraction reflections were shifted towards large scattering angles indicating the presence of tension and lattice deformation.

Differential thermal analysis of the glass was carried out in the temperature range of 20 $1000^{\circ} \mathrm{C}$, both on glass powder (grain size 40-80 microns) and on granule fragments (about 2-3 mm in size) (Fig. 5). The weight of the test samples was constant. 


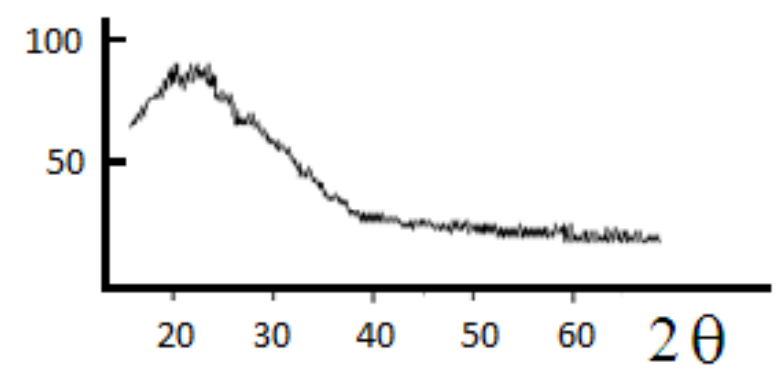

Fig.3. X-ray picture of the melt quenched in water.

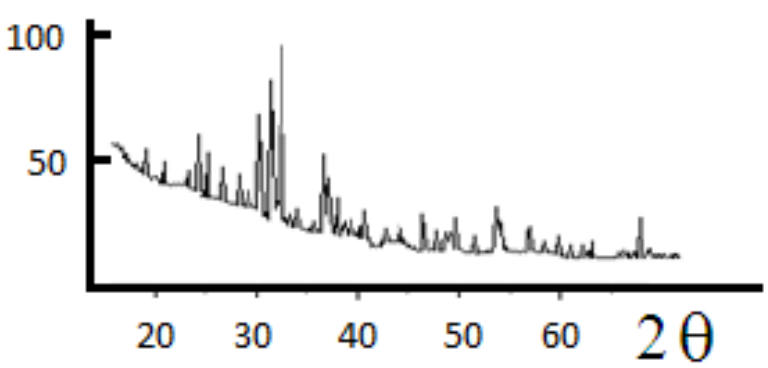

Fig.4. X-ray picture of the melt cooled at a rate of 100 degres/sec (density $300 \mathrm{~W} / \mathrm{cm}^{2}$ ).

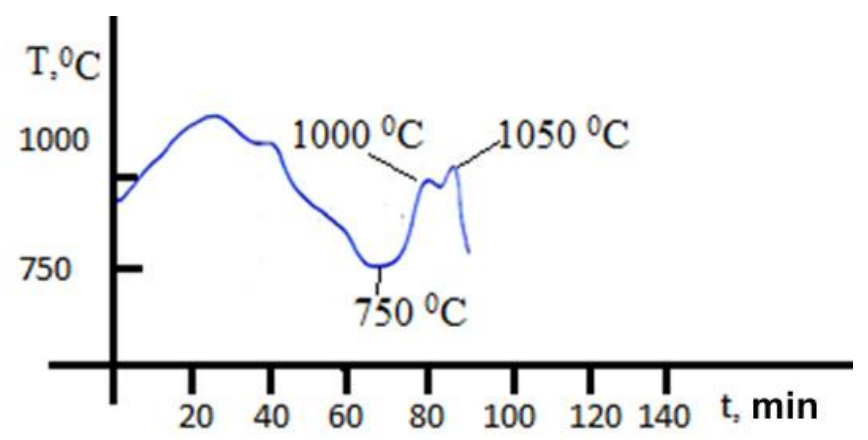

Fig.5. DTA curves of the water-quenched melt (fragments) (density $300 \mathrm{~W} / \mathrm{cm}^{2}$ ).

According to the Figure 5, the DTA curve of the fragments have reached one endothermic $\left(750^{\circ} \mathrm{C}\right)$ and two exothermic peaks at $\left(1000,1050^{\circ} \mathrm{C}\right)$. The picture indicated that the crystallization process went in two stages: in the range $750-1000^{\circ} \mathrm{C}$, a rigid crystalline framework forms; while between the temperatures $1000-1100^{\circ} \mathrm{C}$, the main crystalline phase occurs in the form of diopsidehedenbergite.

Diffraction patterns of material synthesized at different flux density is shown in Figure 6. Material synthesized at flux density of $100 \mathrm{~W} / \mathrm{cm}^{2}$ consisted of the mixture of augite $(\mathrm{Ca}, \mathrm{Na})\left(\mathrm{Mg}, \mathrm{Fe}^{2+}, \mathrm{Al}, \mathrm{Fe}^{3+}, \mathrm{Ti}\right) \mathrm{Si}_{2} \mathrm{O}_{6}$ and diopside $\mathrm{CaMgSi}_{2} \mathrm{O}_{6}$ phases. Increase of flux density up to $200 \mathrm{~W} / \mathrm{cm}^{2}$ led to transfer of $\mathrm{Fe}^{+}$to $\mathrm{Fe}^{2+}$ and to crystallization of fayalite $\mathrm{Fe}_{2} \mathrm{SiO}_{4}$ and diopsidehedenbergite $\mathrm{Ca}\left(\mathrm{MgFe}^{2+}\right) \mathrm{Si}_{2} \mathrm{O}_{6}$. The material synthesized at $300 \mathrm{~W} / \mathrm{cm}^{2}$ had monomineral diopsidehedenbergite structure.

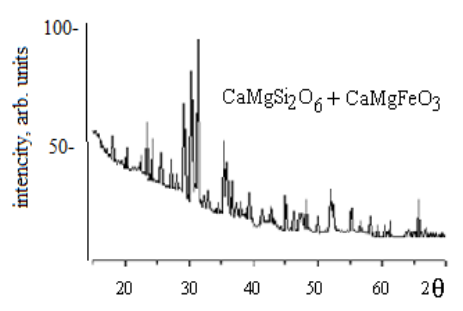

a)

Fig.6 X-ray pictures of pyroxene glasscrystal material synthesized under the different flux density: a) 100 , б) 200 , в) $300 \mathrm{~W} / \mathrm{cm}^{2}$

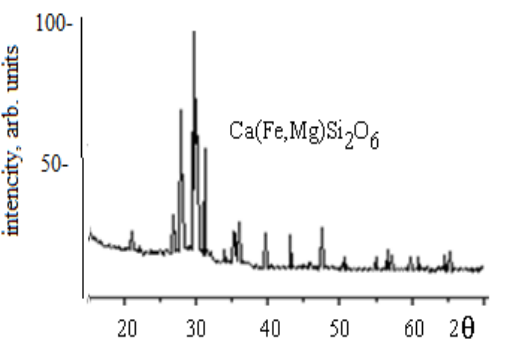

b)

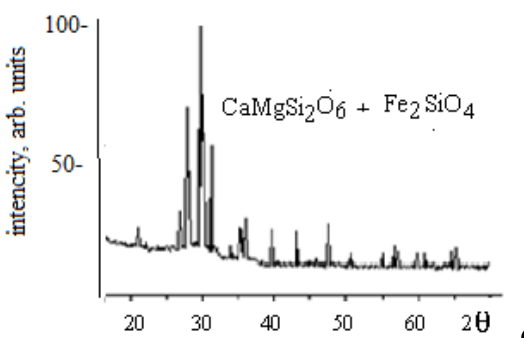

\section{ax}

Differential thermal analysis of powdered samples was similar to that of glass granules. However, the endothermic peak shifted by $20^{\circ} \mathrm{C}$ towards low temperatures, and indicated the presence of insignificant surface crystallization of pyroxene. The analysis of the microstructure by electronic-microscopic images (Fig. 7) showed that synthesized material had a pebbled surface in most cases, it homogeneity grew with the raise of the flux density (Table 2). 
Table 2

Description of the microstructure of fused materials depending on the flux density $(Q)$

\begin{tabular}{|c|l|}
\hline $\mathrm{Q}, \mathrm{W} / \mathrm{cm}^{2}$ & \multicolumn{1}{|c|}{ Microstructure } \\
\hline 100 & $\begin{array}{l}\text { Grains in the form of densely packed polyhedrons of various shapes with particle } \\
\text { size ranging from 1 to 10 microns. }\end{array}$ \\
\hline 200 & $\begin{array}{l}\text { Grains of various shapes in the form of deformed polyhedrons with size ranging } \\
\text { from 1 to 5 microns. }\end{array}$ \\
\hline 300 & $\begin{array}{l}\text { Densely packed grains in the form of polyhedrons of various shapes with particle } \\
\text { size ranging from 0.4 to 1 micron. }\end{array}$ \\
\hline
\end{tabular}

One can also see the presence of pyroxene crystallization nuclei (white), as well as black inclusions of ore minerals. Such inclusions could be phases of $\left(\mathrm{Fe}_{2} \mathrm{O}_{3} \mathrm{FeO}\right)$ of magnetite.

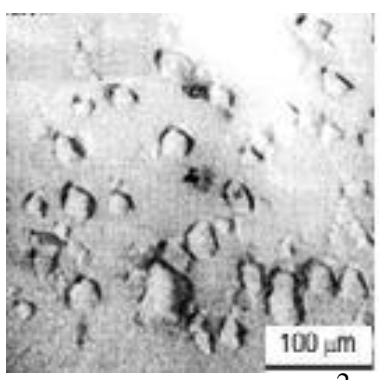

a) $100 \mathrm{~W} / \mathrm{cm}^{2}$

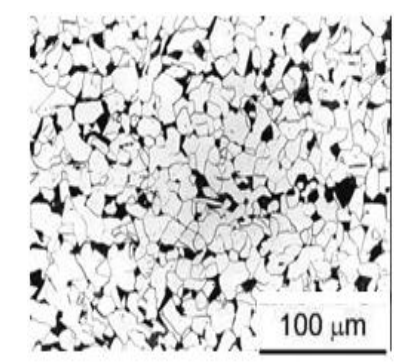

b) $200 \mathrm{~W} / \mathrm{cm}^{2}$

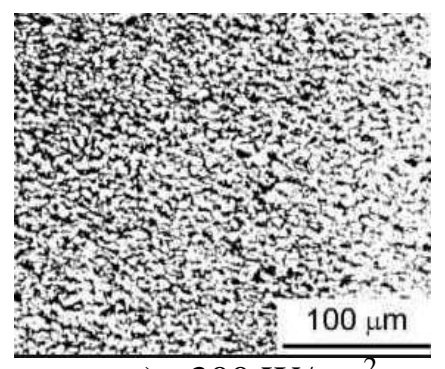

c) $300 \mathrm{~W} / \mathrm{cm}^{2}$

Fig. 7. Electronic microscopic images of glasses obtained at various flux density of concentrated solar radiation

It was found, that if the flux density rose from $100 \mathrm{~W} / \mathrm{cm}^{2}$ to $300 \mathrm{~W} / \mathrm{cm}^{2}$, at a constant cooling rate, the glasses changed color from dark brown to black, which was caused by transition of $\mathrm{Fe}^{3+}$ to $\mathrm{Fe}^{2+}$

The value of the flux density also affects the graininess of the glass (Figure 8). It is seen that with a growth of the flux density, a non-monotonic decrease in the size of glass grains can be observed.

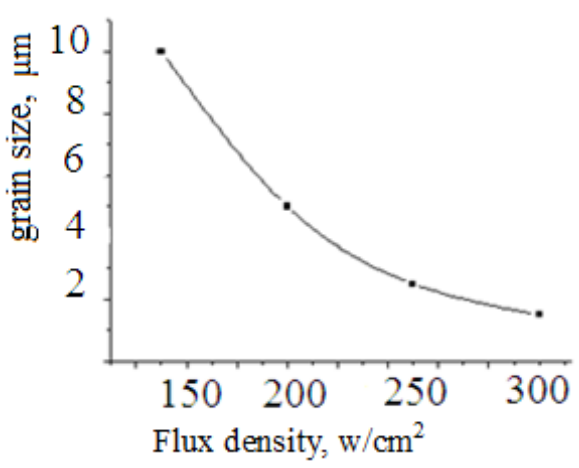

Fig.8. Dependence of the size of the fused glass' particles on the flux density (Vcool $\sim 10^{3}$ degrees/sec)

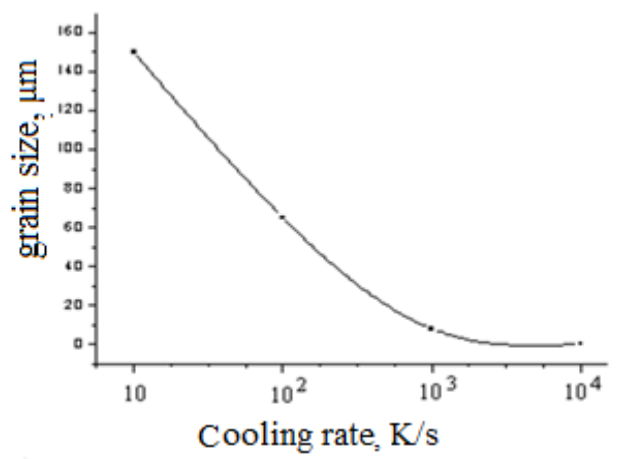

Fig.9. Dependence of the size of particles on the cooling rate

The Fig. 9 represents dependence of the grains size on the cooling rate at flux density of 200 $\mathrm{W} / \mathrm{cm}^{2}$. One can see that the growth of the cooling rate of the melt resulted in grains size diminishing. To obtain a material with grain size of a nanometer, the melt needs to be cooled at the rate of $10^{6}$ degrees/sec.

The Fig. 10 presents dependence of the glass abrasion on the density of the concentrated solar radiation flux. As seen in the figure, the higher the flux density is, the less it is the abrasion 
intenisty of the glass. Obtaining a glass-crystalline material involves directed crystallization of glass at certain temperatures. We used a single-staged crystallization mode, which includes heating up to $1050^{\circ} \mathrm{C}$, followed by slow cooling. Figure 11 shows dependence of the glass crystalline abrasion on the cooling rate of the glass. One can see that the cooling rate of the melt also affected the wear-resistance of the material (Fig.11). The wear resistance of the material obtained by sintering of pyroxenes at different temperatures rises with an increase of the sintering temperature.

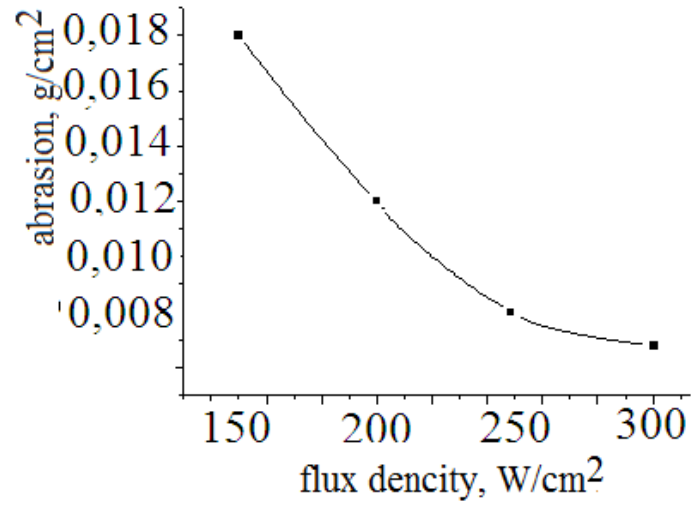

Fig.10. Dependence of the glass abrasion on the flux density (Vcool $\sim 10^{3}$ degree/sec)

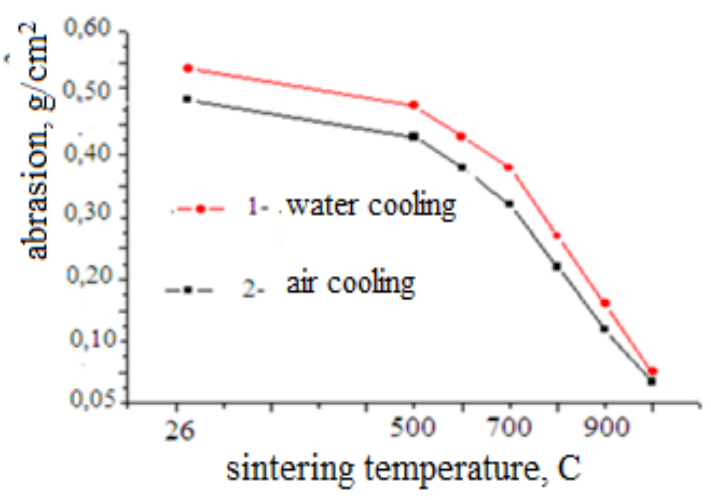

Fig.11. Dependence of the glass crystalline abrasion on the glass cooling rate

A better sintering of the material is achieved owing to improved homogeneity of the glass as well as to increased flux density and grain size distribution. Apparently, the impact of concentrated light radiation on materials is of a threshold nature. There is a critical flux density, which accelerates the speed of structuring or destruction of the material, which are based on the ion diffusion processes.

The water absorption and ultimate strength at bending of glass-based material samples obtained at various flows also varied depending on the flow density (Table 3).

Table 3

Properties of sintered materials depending on the flux density of concentrated solar radiation

\begin{tabular}{|c|c|c|c|c|}
\hline \multirow{2}{*}{ Parameters } & \multicolumn{4}{|c|}{ Flow density, W/cm ${ }^{2}$} \\
\hline & 150 & 200 & 250 & 300 \\
\hline Water absorption, $\%$ & 0,05 & 0,04 & 0,03 & 0,02 \\
\hline Tensile strength at bending, $\mathrm{MPa}$ & 125 & 130 & 140 & 145 \\
\hline Abrasion, $\mathrm{gr} / \mathrm{cm}^{2}$ & 0,018 & 0,012 & 0,008 & 0,006 \\
\hline
\end{tabular}

High flow densities stimulate formation of homogeneous melt and directional crystallization of the monomineral diopside-hedenbergite structure, and determine high mechanical properties of materials. To obtain homogeneous glass, the synthesis has to be carried out at radiant flux densities, that provide significant overheating of the melt $-300-350 \mathrm{~W} / \mathrm{cm}^{2}$. When the radiant flux densities are low, it becomes essential to control the flow rate (heating), since its decrease slows down the phase transformations in the silicate system, as well as it raises the temperature and time of the final stage of thermal treatment.

The higher the flux density, the more intensively the crystalline structure of the material is destroyed, which leads to remaining of fewer zones with an ordered arrangement of atoms in the glass and more of the disordered structures. According to the cluster model, the melt comprises clusters - crystal-like groups and an amorphous zone. Atoms are exchanged between clusters and 
disordered zones. This exchange becomes balanced at a constant temperature - the relative number of clusters and disordered zone do not change. The temperature rise causes suppression of the fraction of clusters and growth of fraction of the disordered zone. The glass phase serves as a "buffer" that relieves the tension arising during the growth of the crystals, limits the freedom of crystal growth and determines the quantitative ratio of crystalline phases, and porosity. Both increased content of crystalline phases and decreased size of the grain contribute to improved strength.

\section{CONCLUSIONS}

The findings showed that during synthesis of materials from the melt using Grand Solar Furnace formation of the amorphous state depends on the cooling rate, which is affected by such parameters as heat transfer conditions, melt temperature, material of the quenching system, etc. In particular melting of pyroxene and following quenching in water led to stabilization of amorphous state.

Cooling rate and flux density influenced on the microstructure and grain size of the synthesized material. Increase of flux density from 100 to $300 \mathrm{~W} / \mathrm{cm}^{2}$ led to grain size decrease from 10 to $1 \mu \mathrm{m}$ (under constant other conditions). Cooling rate increase also resulted in grains refinement.

Variation of the flux density resulted in the change of the synthesized material phase composition. At the flux density of $100 \mathrm{~W} / \mathrm{cm}^{2}$ augite $(\mathrm{Ca}, \mathrm{Na})\left(\mathrm{Mg}, \mathrm{Fe}^{2+}, \mathrm{Al}, \mathrm{Fe}^{3+}, \mathrm{Ti}\right) \mathrm{Si}_{2} \mathrm{O}_{6}$ and diopside $\mathrm{CaMgSi}_{2} \mathrm{O}_{6}$ phases were formed. Increase of flux density up to $200 \mathrm{~W} / \mathrm{cm}^{2}$ led to to crystallization of fayalite $\mathrm{Fe}_{2} \mathrm{SiO}_{4}$ and diopside-hedenbergite $\mathrm{Ca}\left(\mathrm{MgFe}^{2+}\right) \mathrm{Si}_{2} \mathrm{O}_{6}$. The material synthesized at $300 \mathrm{~W} / \mathrm{cm}^{2}$ had monomineral diopside-hedenbergite structure.

The formed homogeneous microstructure with an optimal combination of crystalline and amorphous phases contributes to an increase in the wear resistance of the material on $12 \%$.

\section{Acknowledgments}

The authors are grateful to the research associates Akbarov R.Yu.and Nurmatov Sh.R. for taking part in the experiments and discussing the findings.

This work has been carried out at the financial support from the Ministry of Innovative Development of the Republic of Uzbekistan; Grant Nr. FI FA-F-3-02.

\section{References}

Abdurakhmanov, A.A., Faiziev, S.A., Akbarov, R.Y., Suleimanov, S.K., Rumi, M.K. Properties of pyroxene glass ceramics, heat treated in the Big Solar Furnace, Applied Solar Energy, vol. 45 (1), pp. 45-47, 2009.

Abdurakhmanov, A.A., Paizullakhanov, M.S., Akhadov, Z. Synthesis of calcium aluminates on the big solar furnace, Applied Solar Energy, vol. 48 (2), pp. 129-131, 2012.

Akbarov, R.Yu., Paizullakhanov, M.S. Characteristic features of the energy modes of a large solar furnace with a capacity of 1000 kW, Applied Solar Energy, vol. 54(2), pp. 99-109, 2018.

Andreyev, V.M., Grelihus, V.A., Rumyantseva, V.D. Photovoltaic conversion of concentrated solar radiation, Leningrad: Nauka, 1989 (in Russian).

Atabaev, I.G., Paizullakhanov, M.S., Faiziev, Sh. A. Structure Formation in the System $\mathrm{TiO}_{2}-$ $\mathrm{BaCO}_{3}$ in Concentrated Solar Radiation, Glass and Ceramics, No 3-4, pp.14-17, 2016.

Atabaev, I.G., Paizullakhanov, M.S., Faiziev, Sh., Shermatov, Z.. High-strength glass-ceramic materials synthesized in a large solar furnace, Applied Solar Energy, vol. 51, No. 3, pp. 202-205, 2015. 
Fernández-González, D., Prazuch, J., Ruiz-Bustinza, I., González-Gasca, C., Piñuela-Noval, J., Verdeja, L.F. Solar synthesis of calcium aluminates, Sol. Energy, vol. 171, pp.658-666, 2018.

Fernández-González, D., Ruiz-Bustinza, I., González-Gasca, C., Piñuela-Noval, J., MochónCastaños, J., Sancho-Gorostiaga, J., Verdeja, L.F. Concentrated solar energy applications in materials science and metallurgy, Sol. Energy, vol. 170, pp. 520-540, 2018.

Paizullakhanov, M.S. The pyroxene composition glass crystalline materials, Computational nanotechnology, No. 2, pp. 101-105, 2016.

Paizullakhanov, M.S., Payziyev, S.D., Suleymanov, S.K. Modeling of Processes of Heating and Cooling of Materials in a Solar Furnace, Appl. Sol. Energy, vol. 55, pp. 404-408, 2019.

Riskiev T.T., Paizullakhanov, M.S., Atabaev, I.G., Faiziev, Sh.A. The Effects of the Solar Radiant Flux Density on the Properties of Pyroceramic Materials, Applied Solar Energy, vol.50, No 4. p.260-264, 2015.

Hiller Ya. A., Tables of Interplanar Spacings, Moscow: Nedra, 1966 (in Russian). 